Journal of Advanced Research in Fluid Mechanics and Thermal Sciences

\title{
Weld Bead Surface Defects Formation and Its Implications - A Review
}

\author{
Muhamad Hellmy Hussin ${ }^{1, *}$, Nur Azida Che Lah ${ }^{1}$ \\ 1 Fabrication and Joining, Universiti Kuala Lumpur Malaysia France Institute (UNIKL MFI), Seksyen 14, Jalan Teras Jernang, 43650, Bandar Baru \\ Bangi, Selangor, Malaysia
}

\begin{tabular}{ll} 
ARTICLE INFO & ABSTRACT \\
\hline Article history: & The present work reviews and interprets weld bead's patterns especially on solidified \\
Received 30 November 2019 & weld surfaces. Defects patterns such as rippling, humping, and other unexpected \\
Received in revised form 1 February 2020 & surface patterns appearances have been found to be influenced by welding \\
Accepted 4 February 2020 & parameters such as welding current and travel speed. These welding defects usually \\
Available online 30 June 2020 & $\begin{array}{l}\text { accompanying with other serious deterioration such as undercut, porosity and } \\
\text { segregation which clearly decrease the joint's strength properties. }\end{array}$
\end{tabular}

Keywords:

Defects; weld bead; weld strength

Copyright $\odot 2020$ PENERBIT AKADEMIA BARU - All rights reserved

\section{Introduction}

Connecting one pipe to another is much more of a labour intensive process as it requires welding, threading, or flanges along its relevant equipment. Although this type of steel encompasses many variety of elemental compositions which basically contain mostly iron, there are several other metal composition that can be added to produce a large effect on its weldability and its strength [1-3]. Welding steel typically requires pre-heat and post-heat treatment in order to prevent weld cracking, whereas welding steel like high carbon steel even more prone to weld cracking and require special welding filler metals. The crack refers to a weld where the weld pool is left unfilled and it results from the shrinkage strains that occurs as the weld metal cools. When the restriction of contraction happened, it will induce the residual stresses that cause cracking. According to that, typical factors that usually combine to cause cracking such as, (i) hydrogen generated by the welding process, (ii) a hard brittle structure which susceptible to cracking, and (iii) tensile stresses acting on the welded joint itself [2,4-6]. It can be said that, the higher carbon equivalent the steel has, the less weldable it is. It means that the weldability of steel with more than $0.2 \%$ carbon content were considered to be poor due to the high hardness and high potential for the steel to crack. In comparison, low carbon steel shows to have advantage and the most readily welded steel in a room temperature

\footnotetext{
* Corresponding author.

E-mail address: hellmy@unikl.edu.my

https://doi.org/10.37934/arfmts.72.2.4155
} 
environment. Instead of that weld cooling rate is also vital during steel selection before welding [49].

In addition to this, many factors contributed to the cooling rate of the welded joint such as the thickness of the steel plate being welded, the carbon content and alloying elements in carbon equivalency and the ambient temperature. Meanwhile, some elements that can found in steel are just not conducive to welding. Despite that, no matter what preheat or filler metal selected to be used during welding process, it was found to be not suitable to the weld itself. Small amount of sulphur and phosphorus are weldable and if the amounts over $0.05 \%$ of either could be prone to solidification cracking [10-14]. One of the welding techniques that widely and typically used in joining the steel is gas metal arc welding (GMAW). GMAW uses a continuous consumable electrode. This type of welding application is often used as it reduces the potential for excessive flux production which causes corrosion in the welded component and structure [15-17].

Although fusion welding such as GMAW, is the largest alloying bond category, as to date, most of the welded joint still provide problems to engineers, researchers, and especially manufacturers. Importantly, the aim is to produce a welded structure that meets and parallel with the required standards [18-22]. Accordingly, scheduled periodic inspections should be carried out to ensure the quality of welding is in good condition. During the welding process, high heat sources are produced by arc and rapid heating and cooling lead to corrosion and phase changes in different zones in welded structures [23-24]. A wide variety of high energy heat sources used during welding that includes a gas flame, electric arc, a laser, an electron beam, friction and ultrasound. In addition, the failure of such welding that includes gas porosity defects, imperfection in penetration where the actual root penetration is less than the specified that caused inadequate penetration, fracture, distortion, oxidation, and brittleness has a significant impact on the quality of the structure [25]. The failures that usually occur in welded joint can be categorized according to these important factors which are, (i) presence of defects in the form of physical discontinuities, and (ii) microstructure heterogeneity in welded joint that cause substantial differences on the toughness of the welded joint. Factors such as joint design, the difference in chemical composition between base metals and welded metals, welding procedures, techniques and heat treatment plays an important role in which it can affect the quality of the welded metal produced and (iii) residual stresses [26-30].

\section{Thermal Effects in Welding}

During welding the internal part of rounded pipe, couples of forces subjected to welding such as the impact force given by the burning arc from the welding torch. It is the force where the gravity plays an important role which tends to drop the molten metal during welding took place. The other is the surface tension force where it focused on the surface of weld which can vitally influence the weld bead pattern and contour mainly during solidification process [31-32]. In rounded piping system, the weld contour pattern can really basically affect and gives main impact in the pipe line service life. A poor or improper welding technique also become one of the main factor that can affect the weld contour especially in the first weld pass. Improper technique welding usually includes poor shielding gas coverage or incorrect travel speed that can cause weld excessive spatter. This condition could lead to weld defects. Instead of that, faulty welding technique and poor weld hygiene generally cause porosity. It is also can downgrade the deposition of the subsequent weld passes. It also can lead to local turbulent flows mainly at internal inner piping surface. Thus, would induce erosion and corrosion phenomenon at the inner parts of the piping streamline. High fluids and hot gas velocity also can create catastrophic turbulent flows which can chip-off the metal surface leaving a porous 
metal surface. These effects would weaken the weld beads and allow the gases to penetrate inside the subsurface of the metal whereby will create chemical reaction [33-37].

More complex conditions occur when it involves the oxidation of a welded structure in which the welded structure itself has different phase changes, composition, microstructure, and presence of defects in the welded metal parts that contribute to the reduction of the weld's performance. Factors such as joint design, the difference in chemical composition between base metals and welded metals, welding procedures, techniques and heat treatment plays an important role in which it can affect the quality of the welded metal produced. One of the basic principle that contribute to good joint design and its geometry is one that uses correct root openings and groove angles that require the least amount of weld metal and give proper accessibility to the joint's root. Another factor is the difference in chemical composition which is basically related to the selection of filler metal whether it is alloys or unalloyed metals which when heated, liquefy and melt and smoothly flow into the space and creating a weld connection [25]. The correct choice of filler material can produce a welded joint with optimum properties in respect of strength, corrosion resistance and weld cracking. In addition to the welding technique factor to improve the weld quality, some technique that has been discussed or tips to follow such as increase the welding current, cleanliness of the joint before welding, proper electrode angles, effective manipulation of welding gun and its travel speed. All of these factors determined a good weld quality and become an indicator to prevent the formation of crack and other weld imperfections [26, 35]. Indirectly, it affects the performance of the weld structure depending on the particular exposed to the environment and condition. Jodia $[12,38]$ found that rough surfaces on the weld structure design also affected the oxidation effect, while the oxidation rate was influenced by the oxide layer thickness. Although composition and microstructure changes are low, it still influences the potential of electrochemistry between the zones in the welded structure [3942].

Nowadays, the welding is carried out by a robot and less defects produced compared to the early days where the welding process was carried out and handheld manually. In some cases, where the welding need to be controlled by the workmanship of the welder especially during maintenance and repair services, the causes of the defects need to be thoroughly monitored. In other words, the welder needs to make a good bridge in order to match the weld joints [43-47].

\section{Metallurgical and Mechanical Aspects}

Welding is a high-temperature process. In the welding process, the macrostructure for zone division in fusion welding is shown in Figure 1. The perfect welded structure has three main zones, which are (i) welded metal zone, (ii) base metal (BM), and (iii) heat effect zone based on the types of metal that being welded $[8,48]$. Welded metal zone is a welded area where metal melted with combination of base metal and filler metal. The next region which is closely near to the weld metal zone is the heat-affected-zone (HAZ). The metal in this HAZ region does not melt and thus, definitely affects by the heat produced during the welding procedure takes place. Moreover, the HAZ is very critical area since embrittlement is concentrated and most of the defect usually initiated in these zones [10]. The third zone is the base metal (BM) in which this zone is not affected by the process of heating and melting of metal during welding and typically free from serious defects [49-51]. 


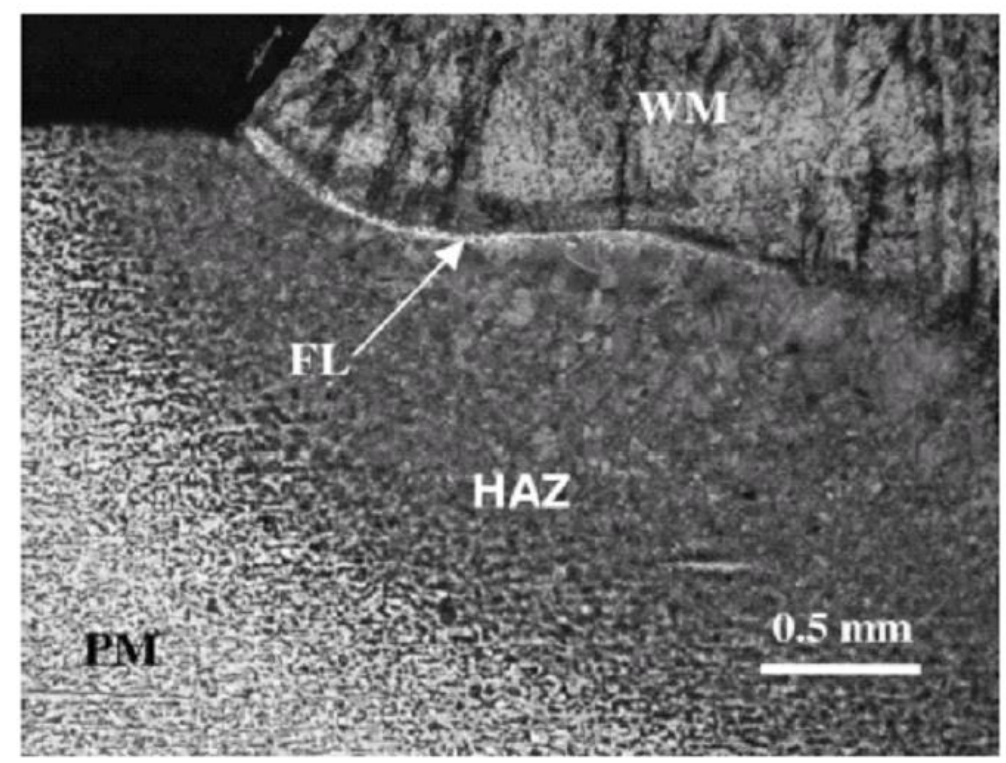

Fig. 1. The optical image of the welded structure shows the welded metal part, base metal (BM), fusion line (FL) and heat affected zone [3]

Solidification of metal plays an important role in understanding the state of microstructure and non-homogeneous chemical state in the welded joint. When metal parts are subjected to heating at high temperatures during the welding process, the base metal melted and the added filler metal will solidify with a non-uniform chemical composition [52-53]. Whereas, the geometry of the welded joint and the thermal cycles involved are influenced by thermal conditions and fluid movements. The growth of the grains is eventually formed by the arrangement of atoms that grow from the base metal. In the case of fusion welding involving the addition of filler metal, solidification welded joint is formed and new grain growth begins at heterogeneous locations at welded metal boundaries. Thus, the welded metal zones formed a non-uniform orientation. Boumerzoug et al., [24] reported on the solidification microstructure of low carbon steel and they showed that welded joint area are characterized by the presence of very large grains near the fusion line and these grains are oriented and located along the directions of the large heat flow.

As reported by Bodude et al., [25], the effectiveness of weld joint usually rely on its strength, heat distribution ability which includes the response variations that are monitored by welding current, arc voltage and welding speed typically during welding A36 carbon steel. They proved that finer grains size formed at weld zone of high tensile strength. In addition, they also observed that the grain size is larger at HAZ. As well known, weld metal or weld deposit are the welding area that experienced higher heat than the HAZ area and that caused the different pattern of weld microstructure. As indicated by Budiarto et al., [26], they showed that the weld metal characterized by long-grained structure or columnar grains pattern due to heat experienced during welding process as shown in Figure 2. Al-Saraireh [27] stated mainly on the changes of mechanical properties behavior of material as a function of temperature, loading etc. She reported that as the temperature increase above room temperature, it can cause a decrease in strength properties of metallic alloys which includes ductility, fracture toughness and elongation. Both of the study by Gupta et al., [28] and Al-Saraireh [27] are in agreement as they showed that finer grain size microstructure indicates high tensile properties and coarse-grain size indicates lower hardness and low strength value especially for A36 carbon steel [5459]. 


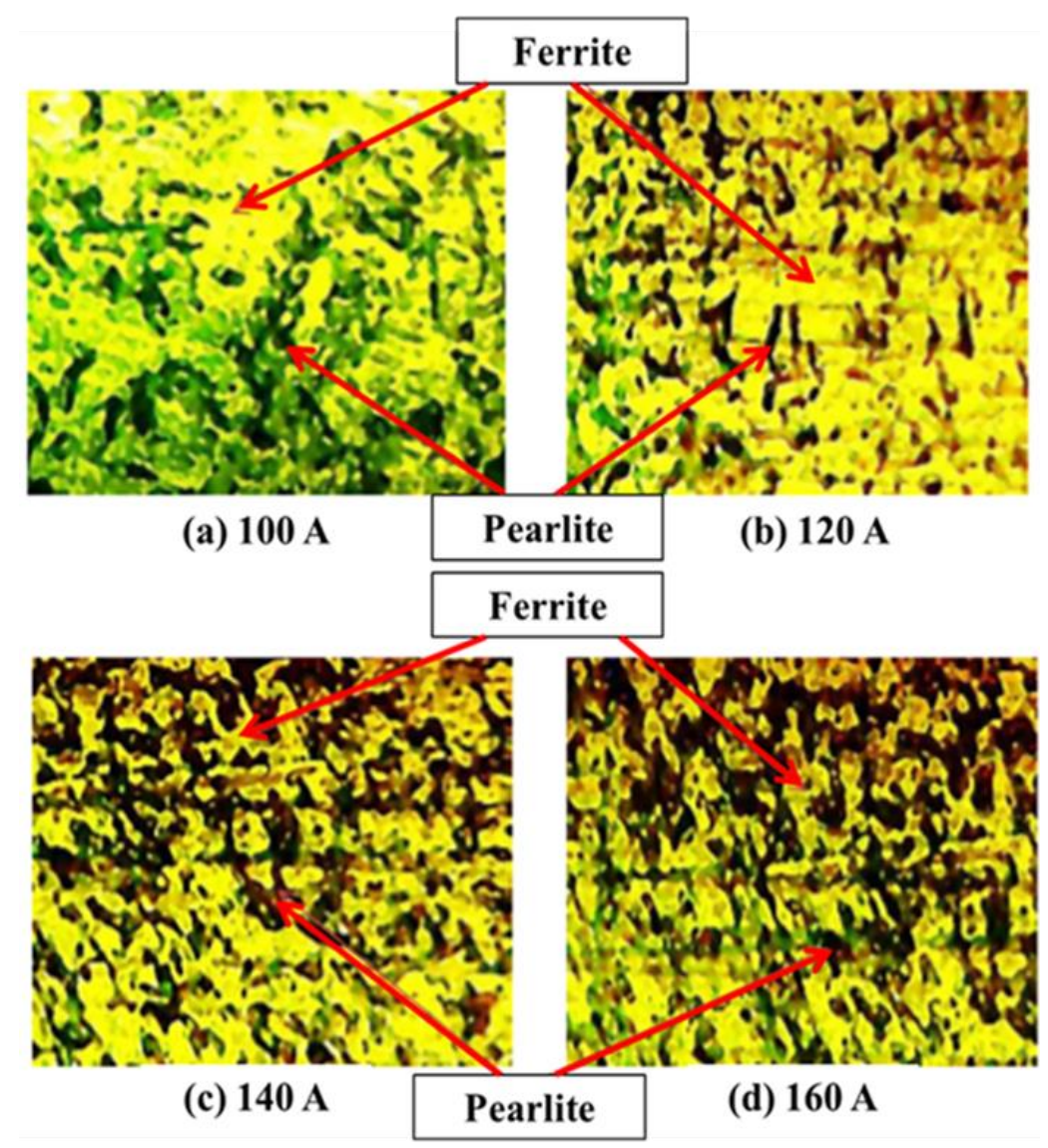

Fig. 2. Microstructure of steel 37 at different welding current [12]

The part closest to the fusion boundary is called HAZ area where the part experiencing high thermal cycling and sudden air cooling. This part enables the grain growth and sudden coarsening of grains as well as phase changes from austenite into martensite phase [60]. Austenite or $\alpha$-phase Fe is a metallic non-magnetic solid solution of Fe and an alloying element such as $\mathrm{C}$. It is a high temperature phase and basically it has has face centered cubic (FCC) structure. Meanwhile, martensite refers to a very hard constituent of steel. It is formed by rapid cooling of austenite which traps carbon atoms that do not have time to diffuse out of crystal structure. Uzun [11] discussed on martensitic transformation in LCS. They stated that this martensitic form is extremely hard and they proved that increasing carbon content increases the effect of martensitic transformation [61].

It is reported by Jodia [12] that as the heat input increase from 100 to $160 \mathrm{~A}$, the microstructure become coarser and the pearlite phase was greater than ferrite phase as shown in Figure 2. Pearlite is a mixture of two phases, ferrite and cementite. It forms by the cooperative growth of both of these phases. Asibeluo and Emifoniye [29] found that increasing current from $70-120 \mathrm{~A}$ caused a corresponding increase in the temperature of the welded joint and it affects the weld microstructure. Silva et al., [16] found that the microstructure of medium CS revealed the predominant coarse ferrite grain matrix (white) in pearlite distribution (black) indicating no changes in microstructure due to heat generated at the weld. Their study was found in agreement with Jodia [12] and Budiarto et al., [26] that characteristics of metallurgy especially in the weld metal and also in HAZ are very prominent. This is because of its direct influence behavior of the weld to the mechanical properties and joint performance. It is well described earlier that the different characteristics between WM, HAZ and $\mathrm{BM}$ are related with the distributions of pearlite, ferrite and grain size which is mainly depends on the weld condition adopted [62]. 
Weld metal composition is variable depending on welding condition. In contrast, the HAZ composition is the same as that of base plate and the HAZ is defined as the volume of base material which is structurally affected by thermal cycle. For example, in low carbon steel, the final transformation product in $\mathrm{HAZ}$ at high temperature phase in the range of $1100^{\circ} \mathrm{C}$ close to $1530^{\circ} \mathrm{C}$, is expected to be austenite. In addition, increase in austenite grain size can be effectively enhances the formation of unfavorable microstructural constituents and the coarse austenite grains can transform to a coarse structure such as Widmanstatten ferrite side plate and upper bainite and resulting in a loss of strength and toughness in the weld. As reported earlier, it is suggested that the only way to eliminate coarse grains would be by reducing the heating rate during welding in the range $800-1100$ ${ }^{\circ} \mathrm{C}$, thus the phase changes can be controlled [50,54].

As discussed by Afoegba [31] and Budiarto et al., [26] fast cooling rate during heat treatment process produces finer grain structure which imparts higher hardness of A36 CS welded joint. It is well understandable the role that plays by ferrite and pearlite phases. As the percentage of ferrite (white) is more than pearlite (black), it shows that there is enough time for the molecular structure to move. It indicates that the grain size is big because there is proper diffusion and the carbon percentage is low. Meanwhile, as a result of having more percentage of pearlite (black) than ferrite (white), there is no enough time for the molecule to move and distribute evenly. Since the grain size is small and insufficient time for carbon to redistribute because of no proper diffusion due to fast cooling rate. Thus, it is important to note that, the microstructure has clear and important effects on the mechanical properties of the welded joint such as the hardness, ductility, yield strength and the hardening of the sample [63-64].

\section{Weld Bead Geometry and Defects}

Controlling the weld bead shape is prominently important as the mechanical properties of welds can vitally affected the weld bead shape. Moreover, it is clearly justified that selection of the welding process parameter is important in order to provide good weld quality. Various welding method with varied techniques were employed to provide the best weld bead shape including selecting accurate welding parameters. The aim is mainly to extend or improve the service life of the welded components and to reduce the cost [52].

In metal transfer process during GMAW, the characteristics usually described by the quality of weld bead geometry, weld shape, and droplet transfer [20]. The stability of its characteristics is strongly affected by the distance between the welding torch and arc. As reported by Kursun [3] at low current, the size of the globular metal transfer mode is characterized by the droplet formation. It shows that at low current it provides a periodic formation of big droplets mainly can be found at the end of electrodes. It is described when the metal droplets detached from the electrodes due to gravitational force, specifically described when the droplets dropped into the weld pool. This mode of transfer shows different characteristics if high current applied since the deposition rate is high and it is transferred and transit at spray mode [27,65]. This continuous metal deposition will formed smaller drops and hence produce smooth weld bead and stiffer arc. It is in agreement with Dhas et al., [21] as they applied curvilinear technique analysis that was performed with the predictors to study the weld bead geometry of mild steel. Single pass butt-welding is performed on the commercially steel of IS 2062 grade (C $0.25 \%$, Si $0.20 \%$, Mn $0.75 \%$ and balance Fe) with electrode AWS ER70S-6. They found that bead geometry shows to have direct relation with typical process parameters which includes welding speed, arc current and welding voltage $[17,66]$.

As well known, weld beads microstructure differs when compared to other weld zones. According to Boumerzoug et al., [25] the center of the LCS weld bead is characterised by pseudo-grains and a 
microstructural inhomogeneity is a result of the fastest cooling rates. It is in agreement with Aloraier et al., [32] and Budiarto et al., [26] reported on the weld heterogenous characteristics due to the temperature gradients and the chemical gradients that evolve during the process. Bodude et al., [25] revealed the effects of electrode size towards weld microstructure. They found that coarse pearlite in ferrite matrix became more coarse especially when the grain size increased. It provides an explanation where it relates to the decrease in hardness and tensile strength values as the heat input was increased. It can be said that from the observation by Jodia [12], Afoegba [31] and Budiarto et al., [26], the microstructures with higher concentration of pearlite (black) phase will performed more hardness shows its tendency to reach lower ductility. Besides that, it is not possible to state the direct relationship, but since ferrite grains are nucleated and grow, the growth of the size and distribution location of ferrite and pearlite will depend on time and temperature especially on the cooling rate.

Instead of Hrabe et al., [37], Norfadhlina et al., [38] they performed an intelligent technique using Adaptive Neuro-Fuzzy Inference System (ANFIS) to produce the weld bead width prediction using sets of welding parameters. They also stated that minimization of bead width is important in order to prevent the wastage of the welding electrode and it consumes more time. They performed an analysis on welding with solid wire with gas shielding $\mathrm{CO} 2$ and welding with flux cored wire with gas shielding. It shows that there is a significant influence of heat input and gas flow on weld bead geometry. In addition to that, Norfadhlina et al., [38] studied comparison of weld defects on A36 LCS using two types of shielding gasses which are $\mathrm{CO} 2$ and Argon. They found two types of defects detected on the samples using Argon as a shielding gas which are undercutting and porosity. Meanwhile, only porosity detected on samples that undergone $\mathrm{CO} 2$ as a shielding gas during welding. The gas pores was found solidified in the weld bead of LCS and the possible causes are atmosphere contamination and excessively oxidized workpiece surface.

According to Shoeb et al., [10] effects produced by arc voltage during welding also shows some significant behaviour on the weld bead shape. Higher arc voltage resulting in a wider weld bead and reduction in height because it involved the same weld metal. They suggested that the weld bead width increased from 4.26 to $6.18 \mathrm{~mm}$ as the arc voltage increased. As proposed by them, this condition could be attributed by an increment of the arc length resulted in large spread of the arc and its base [67]. Besides that, it also attributed mainly by a hotter arc which means that because of hotter arc, it leads to a high fluid state of deposited metal. In addition to that, the plasticity and toughness of weld metal are influenced not only by the amount of oxide inclusions but also their shape. It is reported that inclusion globular shape is more favourable and high melting inclusions of irregular angular shape result in greater plasticity and less toughness $[25,65]$. Thus, it is necessary to give careful attention during welding process parameters selection to get a desirable weld quality $[31,68]$.

Bodude et al., [25] found that the V-grooved edge welded joint shows to have high amount of weld deposit. This increased the residual stresses in the WM and HAZ area and they found that the residual stresses significantly affect the mechanical properties of the LCS weld joint and reduction in strength and hardness of the WM and HAZ. As reported by Aloraier et al., [32] high hardness values were recorded on mild steel with single weld bead and the values decreased significantly after depositing subsequent beads. Instead of that, they also revealed that the coarse-grained HAZ area on single weld bead was fully refined after depositing the left and right beads. They suggested that the reduction of hardness is due to the internal strain relieving of the martensitic crystals and segregation of carbon atoms to dislocation sites. Besides that, a very high hardness value which is in unaccepted region in the WM and HAZ were relates to the brittleness characteristics. It depends on the martensite quantity and hence, and optimum quantity is required in order to lower the brittleness, whereas too little quantity yields a soft material [69]. 
The presence of gas porosity and the inclusions are likely to cause failure on the mechanical properties of the welded joint. The gap is formed when there is a reaction between the metal and the gas during the welding process. The inclusion was formed from the imperfections of gas removal $[12,48]$. Figure 3 show the types of defects often occur in welded joint as a result of welding processes performed. The most common defects in welded structures are incomplete fusion, lamellar fractures, imperfect welds and tilt slopes. This defect can also cause failure in a building structure. Non-homogeneous microstructures at weld boundaries also have significant implications and are the cause of failure of such welded structures such as hydrogen cracking, corrosion and stress corrosion cracking $[2,70]$.

Arivazhagan et al., [72] also found that the effects of surface morphology cause the pores to grow in the form of planes, concave, and convex on the same substrate. Different porosity growth rates are due to differences in curvature radius. This shows that during the oxidation process, the strength of the electric field increases or decreases with the increase and decrease of the bottom of the pit whether it is in the form of converging or diverging. Thus, this effect leads to an increase or decrease in growth rates $[17,70]$.

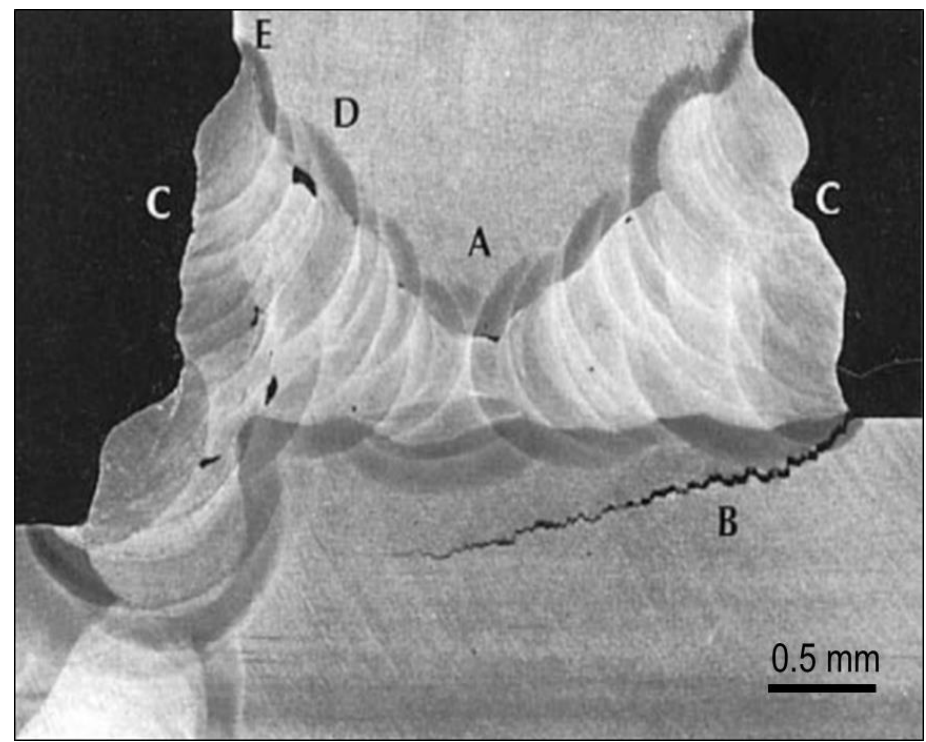

Fig. 3. Defects in welded structures, $(A)$ incomplete fusion, (B) lamelar fracture, (C) imperfect weld profile, (D) porosity, (E) undercut [30]

Instead of weld joint failures due to the presence of defects and residual stresses, the failures encountered due to typical feature of weld joint microstructure would also be the related reasons. These also include hot cracking in weld joint, weld decay, lamellar tearing, stress relief cracking, and local brittle zone in HAZ region [30, 70]. The HAZ region of a carbon steel or alloy steel is that zone which can initiate brittle fracture at low stress levels. As reported by Wei [33] and Aloraier et al., [32], all of them were in agreement with Bhattacharya [73] discussed on the failure of weld microstructure. Despite that, Bhattacharya [73] reported disagreement where not all regions in HAZ are bad for the performance of a weld joint against mechanical loading or corrosion degradation. He stated that in most cases, only a narrow zone in a HAZ is harmful and the presence of coarse grain martensite and upper bainite in fusion weld is the most common problem encountered.

As discussed earlier, it can be said that most common problem encountered are basically is how to choose and control the process input parameters in order to obtain a good welded joint with required weld bead geometry and weld quality. It is also a common requirement to produce a good 
welded joint with minimal detrimental residual stresses and distortion. Kolahan et al., [74] introduced optimization method in GMAW weld bead geometry prediction which is time-consuming, less error development effort and produce more ideal welding parameters combination using ANOVA. They found that the proposed method were efficiently and accurately determine the desired weld bead geometry and its main welding specification [71].

As shown in Figure 4 and 5, effects from welding speed and current definitely resulted in by the appearance of welding defects such as rippling, humping and undercutting. In order to understand the weld bead with irregular formation as known as rippling, it exhibit with arc-shaped topographic features on solidified surface. It was found slightly elevate above the weld's surface at the solidified region $[71,74]$. Meanwhile, humping is more complicated welding beads formation. It is irregular with unpredictable surface contour. It comprised of formation of abnormal appearance like swelled protuberances as indicated in Figure 6 . These humps usually accompany with serious defects like undercut that frequently occurred at the edge of the fusion boundary. Instead of that, another microstructure features such as porosity, solute segregation, fracture and crack also can be found closely related with the weld beads formation. In overall, all these types of defects formation were found strongly deteriorate the strength of the joint properties [72].

Good or poor weld beads formation usually depends on the welding technique that is presented depends on rippling and humping on a solidification weld surface. Wei [33] reviewed that surface ripples on weld bead surface can be reduced by reducing the content of nitrogen when welding using GTAW on high manganese stainless steel. He also discussed the results from previous investigator suggested that the ripples on the steel welds surface were found in good condition for welds that exhibiting poor penetration. Whereas, coarse weld bead surface was found for those with good penetration [28, 72].

In comparisons, morphologies of humped welds indicate complicated rough surface which appeared like gouging region with beaded cylinder-shaped patterns. Most of these kinds of defects occur due to high currents and travel speeds. As indicated in Figure 5, the open bead's pattern with unfilled dry spots between the humped beads confirms and irregular shapes with high probability of defects initiation. In some location, it's having parallel grooves clearly observed at the edge of bead's region and it is confirmed the sign of undercutting defects. Its characteristics of split beads that is separated by an empty channel with disconnected protuberances can be clearly visualized. Based on observations, it can be said that the surface morphology appearances are directly related with beam power, welding current applied and travel speed. This phenomenon also leads to an abnormal weld pool with significant surface depression [73].

As well know, most favorable defects such as pitting usually found on the steel weld beads. According to the SEM image, instead of iron oxides, Nur Azhani et al., [75] found a pitting defect on the surface of steel weld beads. According to the SEM image, the pits were found at specific microstructural features in the weld deposit. Most of the previous researchers found pitting defects in welded area, but Murariu et al., [26] identified pitting degradation on base metal of welded pipeline grade ASTM A355P5. This steel pipeline used in petrochemical plant as transfer line between a thermal cracking heater and a column which are part of an atmospheric distillation and vacuum unit. They found the welded area is degraded by selective leaching phenomena as indicated by the presence of color change. Instead of pitting, non-metallic inclusions such as oxides and silicates were found on the base metal area [26, 74].

Garcia et al., [76] reported on the weld bead characteristics and its relation with the failure causes which may reduce the life span of steel structure and it is in agreement with Nur Azhani et al., [75], Votava [34] and Murariu et al., [26]. The researchers found that corrosion behaviour of welded joints can be affected by compositional and microstructural alterations resulting from the heat cycles 
during previous welding process. All of these factors may create gradients in microstructures, chemical compositions and grain size variations leading to galvanic corrosion [33]. Instead of that, the toughness of the welds steel thin sheet with surface oxidation degraded, because of the small amount of oxygen content, it was still comparable to the toughness of the welds without surface oxidation. No oxide inclusions and porosity were found in the weld metal and the grain size was quite large. It seems that the oxide film in thin sheet steel metal decomposes during laser irradiation and a small amount of oxygen is dissolved in the weld metal. They found that only a small amount of oxygen is retained in the weld pool because of the low solubility of oxygen in liquid iron $[35,75]$.
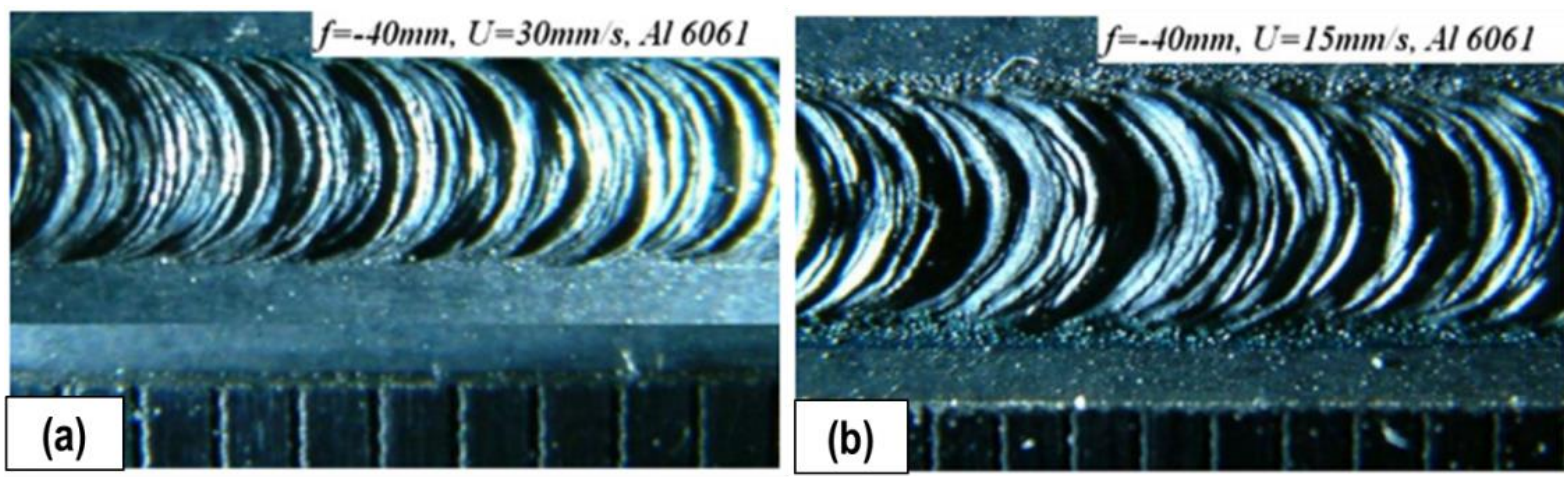

Fig. 4. Rippling surfaces on Al 6061 weld bead for welding speed of, (a) $30 \mathrm{~mm} / \mathrm{s}$ and (b) $15 \mathrm{~mm} / \mathrm{s}$ [70]
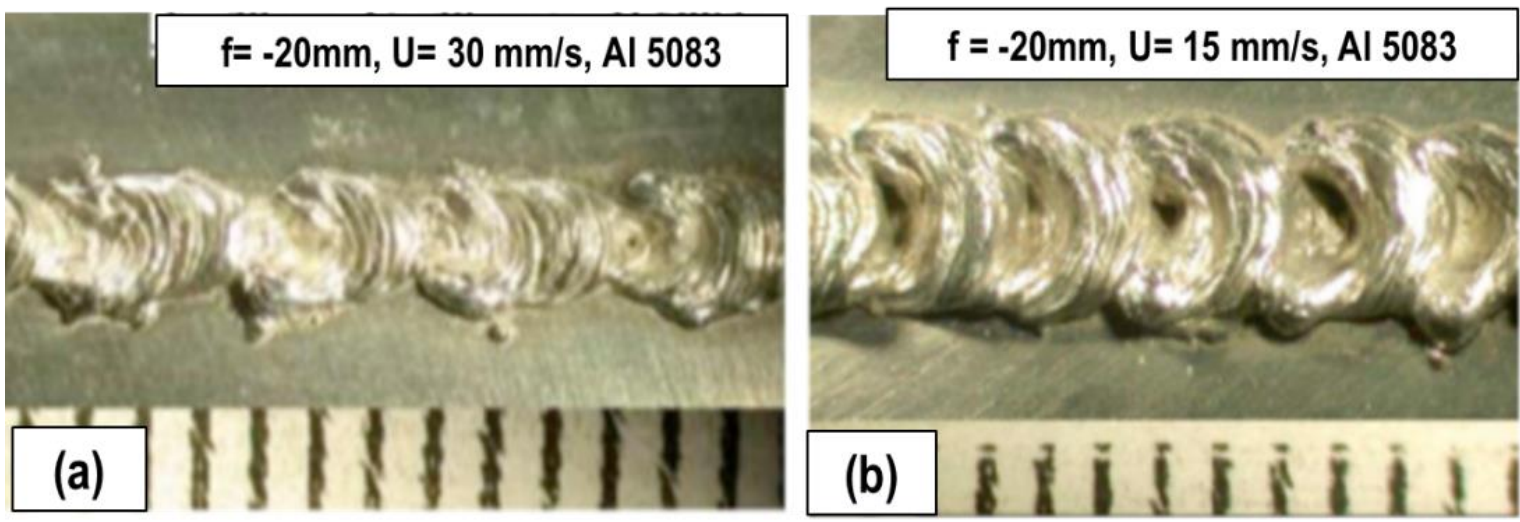

Fig. 5. Humps on weld beads using electron beam welding (EBW) for different welding speed [70]

It is different when compared with Potapov [31] and he reported that the weld metal oxygen content in submerged arc low-alloy steel welds, as well as in steel welds is dependent on the concentration of oxides decomposed at low temperatures in a weld pool slag phase. It was found that the oxygen is mainly in the form of fine dispersed oxide inclusions of less than $0.03 \mu \mathrm{m}[25,76]$. Besides that, microscopic slag inclusion precipitation along the grain boundaries would promote crack initiation in deformed weld metal and also oxide inclusion in ferrite. All of these would serve as stress concentrators and when a stressed state is developed in a metal at the moment of applying an external load, oxides would then promote crack propagation [77-78]. 


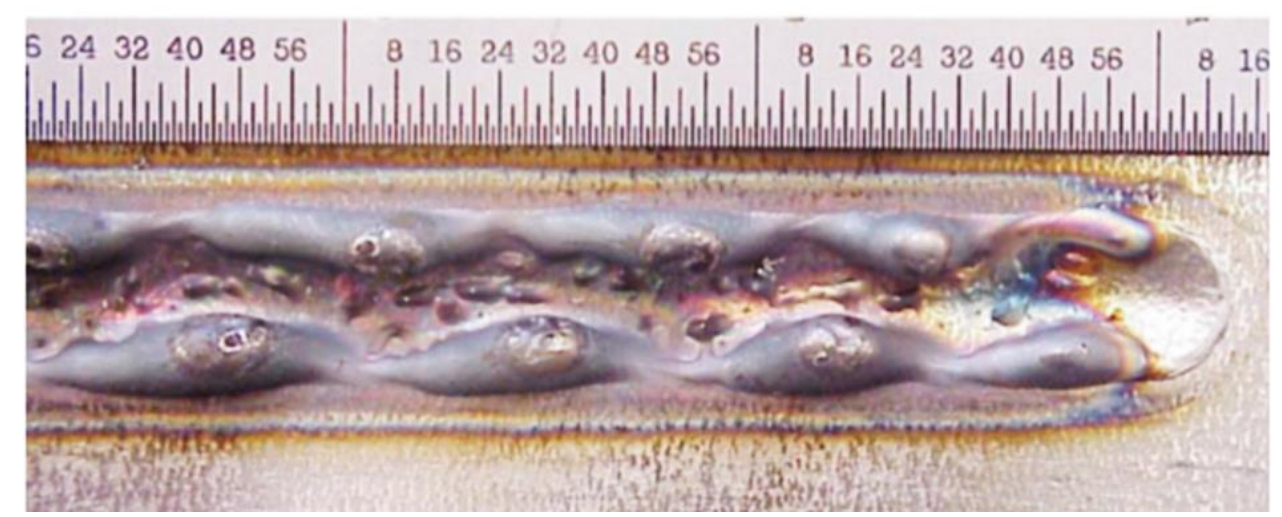

Fig. 6. Humps on weld beads using electron beam welding (EBW) for different welding speed [70]

Improving weld quality becomes an important issue in order to produce good weld with uniform width, an even ripples and well feathered into the base metal and no sign of burning due to overheating. The weld also has good penetration and is free of gas pockets, porosity or inclusions. Instead of that, the skill level of the welder is an important factor in the delivery of high-quality welds. Experienced welder has proper manipulation welding techniques and has certainty in manoeuvres the electrode angles, welding gun, and controlling the travel speed effectively. Meanwhile, several techniques were applied in order to minimize the weld imperfection such as correct selection of shielding gas to protect the molten metal from impurities, the cleanliness of the workpiece, and power source setting for proper polarity [76]. In addition to that, due to enhancement of technology, laser welding is an excellent substitute to the arc welding process. This method shows to have distinct advantages over other welding process such as great for thin materials, capable of welding thicker section, minimal shrinkage and distortion [79]. Another technique like ultrasonic metal welding were chosen as an option in order to overcomes many of these difficulties and imperfections by using high frequency vibration and applied pressure to create a solid-state weld. Thus, this type of welding process offers an enhancement of weld strength and quality [80].

\section{Conclusions}

In this review, inherent characteristics of weld bead geometry such as rippling, humping, and other unexpected surface patterns appearances are different to one another. Instability of welding parameters applied reveals the tendencies of irregular surface morphologies to occur whether it leads to decreasing or increasing the weld strength properties. Additionally, study on weld bead pattern formation is challenging and need to be emphasized with practical and academic importance.

\section{References}

[1] Bakar, S. R. S., Ahmad, M. Y., Ibrahim, M. F. A., Jalar, A., Djalil, S. J. S., and Othman, N. K. "The effect of double pass GMAW process on microstructure and mechanical properties of AA 6061-T6 joining plates." Advanced Materials 12, (2012): 98-104. https://doi.org/10.4028/www.scientific.net/KEM.510-511.98

[2] Amil, Mohd Azril, and Muhammad Adil Khattak. "Relationship between Stress Intensity Factor and Fractal Cracks Propagation in AISI 410 Steel." Journal of Advanced Research in Materials Science, 44, no. 1 (2018): 33-38.

[3] Jehad, D. G., G. A. Hashim, A. K. Zarzoor, and CS Nor Azwadi. "Numerical Study of Turbulent Flow over BackwardFacing Step with Different Turbulence Models." Journal of Advanced Research Design 4, no. 1 (2015): 20-27.

[4] Alawadhi, Khaled, and M. J. Robinson. "Preferential weld corrosion of X65 pipeline steel in flowing brines containing carbon dioxide." Corrosion Engineering, Science and Technology 46, no. 4 (2011): 318-329. https://doi.org/10.1179/147842210X12695149033891 
[5] Khattak, M. A., A. Mukhtar, and K. Azam Khan. "Common root causes of pressure vessel failures: a review." Advanced Research in Applied Mechanics 21, no. 1 (2016): 22-37.

[6] Khattak, M. A., A. Mukhtar, I. S. Shahid, and M. S. M. Sufian. "A Review on Application of Non Destructive Techniques on Composites." Journal of Advanced Research in Applied Mechanics 20, no. 1 (2016): 12-21.

[7] Arora, Hitesh, Rupinder Singh, and Gurinder Singh Brar. "Thermal and structural modelling of arc welding processes: a literature review." Measurement and Control 52, no. 7-8 (2019): 955-969. https://doi.org/10.1177/0020294019857747

[8] Avent, R. Richard. "Heat Straightening of Steel: From Art to Science." American Institute of Steel Construction, (1988):

[9] Badea, G. E., P. Cret, M. Lolea, and A. Setel. "Studies of carbon steel corrosion in atmospheric conditions." Acta Technica Corviniensis-Bulletin of Engineering 4, no. 4 (2011): 25.

[10] Shoeb, M. O. H. D., M. Parvez, and P. Kumari. "Effect of MIG welding input process parameters on weld bead geometry on HSLA steel." Int. J. Eng. Sci. Technol 5, no. 1 (2013): 200-212.

[11] Khattak, Muhammad Adil, Shahid Zaman, Mohd Nasir Tamin, Saeed Badshah, Syed Mushtaq, and Abdoulhdi Amhmad Borhana Omran. "Effect of Welding Phenomenon on the Microstructure and Mechanical Properties of Ferritic Stainless Steel-A Review." Journal of Advanced Research in Materials Science 32, no. 1 (2017): 13-31.

[12] Suppramaniam, S. Umeesh Kumar, and Syuhaida Ismail. "Critical Construction Activities of the Oil and Gas Projects in Malaysia." Journal of Advanced Research Design 63, no. 1 (2019): 1-9.

[13] Azmi, Mohd Irwan Mohd, and Nor Azwadi Che Sidik. "Numerical Study Model for Solidification and Melting of Nanoenhanced Phase Change Material by Enthalpy Porosity Method." Journal of Advanced Research Design 60,no. 1 (2019): 16-28.

[14] Kamely, M. A., AY Bani Hashim, S. H. Yahaya, H. Sihombing, and H. Hazman. "The effect of multipass cutting in grinding operation." International Journal of Industrial and Manufacturing Engineering 7, no. 3 (2014): 508-511.

[15] Thavamani, P., Bhowmick, A. K., and Khastgir, D. "Effect of ageing on strength and wear of tank track pad compounds." Wear 170, no. 1 (1993): 25-32. https://doi.org/10.1016/0043-1648(93)90347-O

[16] Britt, J. "All about Iron." Techno File (2011):14-15.

[17] Bustreo, A. "All you need to know about the heat-affected zone." The Fabricator (July 2016), https://www. thefabricator. com/article/shopmanagement/all-you-need-to-know-about-the-heat-affected-zone (Last viewed on June 7, 2018) (2016).

[18] Moi, Subhas Chandra, Pradip Kumar Pal, and Asish Bandyopadhyay. "Design Optimization of TIG Welding Process for AISI 316L Stainless Steel." International Journal of Recent Technology and Engineering 8, no. 2 (2019): 53485354. https://doi.org/10.35940/ijrte.B2509.078219

[19] Darmadi, Djarot B., Lingga P. Setiawan, and Shahruddin Mahzan. "Evaluating the GMAW Joint with a Constant Heat Input." Journal of Advanced Research in Fluid Mechanics and Thermal Sciences 54, no. 2 (2019): 142-149.

[20] Paiva, Jane Maria Faulstich de, Sérgio Mayer, and Mirabel Cerqueira Rezende. "Comparison of tensile strength of different carbon fabric reinforced epoxy composites." Materials Research 9, no. 1 (2006): 83-90.

https://doi.org/10.1590/S1516-14392006000100016

[21] Wei, Ong Yong, and Siti Ujila Masuri. "Computational Fluid Dynamics Analysis on Single Leak and Double Leaks Subsea Pipeline Leakage." CFD Letters 11, no. 2 (2019): 95-107.

[22] Zaman, Shahid, Muhammad Adil Khattak, and Mohd Nasir Tamin. "Effects of Welding on the Microstructural Properties of AISI 430 Ferritic Stainless Steel." Journal of Advanced Research in Materials Science 44, no. 1 (2018): 25-32.

[23] Goldberg, F. "Influence of thermal cutting and its quality on the fatigue strength of steel." Welding Journal 52, no. 9 (1973): 392-404.

[24] Boumerzoug, Zakaria, Chemseddine Derfouf, and Thierry Baudin. "Effect of welding on microstructure and mechanical properties of an industrial low carbon steel." Engineering 2, no. 7 (2010): 502. https://doi.org/10.4236/eng.2010.27066

[25] Bodude, M. A., and I. Momohjimoh. "Studies on effects of welding parameters on the mechanical properties of welded low-carbon steel." Journal of Minerals and Materials Characterization and Engineering 3, no. 03 (2015): 142. https://doi.org/10.4236/immce.2015.33017

[26] Turnip, Kimar. "The effect of current gouging arc welding analysis of A283 Gr C steel to the tensile strength, hardness and microstructure." In IOP Conference Series: Materials Science and Engineering, vol. 420, no. 1, p. 012055. IOP Publishing, 2018.

https://doi.org/10.1088/1757-899X/420/1/012055 
[27] Al-Saraireh, F. M. "The effect of current and voltage on mechanical properties of low carbon steel products." International Journal of Mechanical Engineering and Technology 9, no. 3 (2018): 134-142.

[28] Gupta, S., Datla, S. V, Sekhar, C. P., and Sahreef, N. A. "An experimental investigation on A36 carbon steel in submerged arc welded joints." International Journal of Mechanical Engineering and Technology 9, no. 4 (2018): 302-311.

[29] Asibeluo, I. S., and Emifoniye, E. "Effect of arc welding current on the mechanical properties of A36 carbon weld joints." SSRG International Journal of Mechanical Engineering 2, no. 9 (2015): 29-37.

[30] Silva, C. C., de Assis, J. T., Philippo, S., and Farias, J. P. "Residual stress, microstructure and hardness of thin-walled Loe-Carbon steel pipes welded manually." Materials Research 19, no. 6 (2016): 1215-1225. https://doi.org/10.1590/1980-5373-mr-2016-0217

[31] Afoegba, S. C. "An investigation to improve the mechanical properties of A36 weldment." Pyrex Journal of Engineering and Manufacturing Technology 3, no.1 (2018): 1-9.

[32] Aloraier, A. S., Joshi, S., Asadi, M., Alena, R. G., and Goldak, J. A. "Microstructural nad hardness modelling effect of multiple bead deposition in temper bead welding technique." International Journal of Energy and Technology 2, no. 16 (2010): 1-11.

[33] Wei, P. S. "The physics of weld bead defect." Intech (2012): 395-413.

[34] Sehat, M. G., and Farhangdoost, K. "Achieve to desired weld bead geometry for the vessel fillet joints in mobile robotic welding." Tehran International Congress on Manufacturing Engineering (2005): 1-11).

[35] Dhas, J. E. R., and Kumanan, S. "ANFIS for prediction of weld bead width in a submerged arc welding process." Journal of Scientific and Industrial Research 66, (2007): 335-338.

[36] Talabi, S. I., Owolabi, O. B., Adebisi, J. A., and Yahaya, T. "Effect of welding variables on mechanical properties of low carbon steel welded joint." Advances in Production Engineering and Management 9, no. 4 (2014): 181-186. https://doi.org/10.14743/apem2014.4.186

[37] Hrabe, P., Choteborsky, R., and Navratilova, M. "Influence of welding parameters on geometry of weld deposit bead." International Conference on Economic Engineering and Manufacturing Systems 10, no. 3 (2009): 1-4.

[38] Norfadhlina, K., Puteri Zirwatul Nadila, M. Z., and Faisal Ahmad, S. B. "A study of weld defects of gas metal arc welding with different shielding gasses." ARPN Journal of Engineering and Applied Sciences 12, no. 6)(2017): 20062011.

[39] Potapov, N. N. "Oxygen effect on low-alloy steel weld metal properties." Welding Research Supplement (1993): 367-370.

[40] Hanuma, P., and Prasad, K. P. "Finite element analysis of weld bead geometry of micro plasma arc welding titanium (Ti-6al-4v) alloy." Journal of Material Science and Manufacturing Technology 4, no. 2 (2019): 38-57.

[41] Helwig, H-M., F. Garcia-Moreno, and J. Banhart. "A study of Mg and Cu additions on the foaming behaviour of AlSi alloys." Journal of materials science 46, no. 15 (2011): 5227-5236. https://doi.org/10.1007/s10853-011-5460-5

[42] Hendronursito, Yusup, Kusno Isnugroho, David Candra Birawidha, and Muhammad Amin. "Analysis Of Shielded Metal Arc Welding (SMAW) On High Manganese Steel Hammer-mill Crusher."Journal of Mechanical Engineering 16, no. 2 (2019): 93-107.

[43] Hernández-Rodríguez, M. L., M. J. Soria-Aguilar, J. L. Acevedo-Dávila, R. R. Ambriz-Rojas, and F. F. Curiel-López. "Welding input effect on the corrosion behavior and microstructure of heat treated GTAW welds of Inconel 718." Int. J. Electrochem. Sci 14 (2019): 4083-4094.

https://doi.org/10.20964/2019.05.43

[44] Ishak, M., Amir, A., and Hadi, A. "Effect of solution treatment temperature on microstructure and mechanical properties of A356 alloy." In International Conference on Mechanical Engineering Research (ICMER 2013), 1-14. Bukit Gambang Resort City, Kuantan, Pahang, Malaysia: Universiti Malaysia Pahang, 2013.

[45] Karlsson, L., E. Keehan, H. O. Andren, and H. K. D. H. Bhadeshia. "Development of High Strength Steel Weld Metals-." Proceedings, Eurojoin 5 (2004): 13-14.

[46] Keehan, Enda, Leif Karlsson, and H-O. Andrén. "Influence of carbon, manganese and nickel on microstructure and properties of strong steel weld metals: part 1-effect of nickel content." Science and Technology of Welding and Joining 11, no. 1 (2006): 1-8. https://doi.org/10.1179/174329306X77830

[47] Kenéz, Attila Zsolt, and Gyula Bagyinszki. "Pressure Welding Processes of Tubular Parts and Pipe Segments." Müszaki Tudományos Közlemények 11, no. 1 (2019): 109-112. https://doi.org/10.33894/mtk-2019.11.23

[48] Klarić, Štefanija, Ivan Samardžić, and Ivica Kladarić. "MAG welding process-analysis of welding parameter influence on joint geometry." In 12th International Research/Expert Conference Trends in the Development of Machinery and Associated Technology. 2008. 
[49] Kowalkowski, Keith, and Amit H. Varma. "Effects of multiple damage-heat straightening repairs on steel beams." Transportation research record 2028, no. 1 (2007): 67-77. https://doi.org/10.3141/2028-08

[50] Lin, Zidong, Constantinos Goulas, Wei Ya, and Marcel JM Hermans. "Microstructure and mechanical properties of medium carbon steel deposits obtained via wire and arc additive manufacturing using metal-cored wire." Metals 9 , no. 6 (2019): 673. https://doi.org/10.3390/met9060673

[51] Mohammed, R. A., M. Abdulwahab, and E. T. Dauda. "Properties evaluation of shielded metal arc welded medium carbon steel material." International Journal of Innovative Research in Science Engineering and Technology 2, no. 8 (2013): 2013.

[52] Amil, M. A., Gaafar, M., Rahman, M. D. A., and CheRos, M. R. "Optimization of surface roughness on 6061-T6 aluminium alloy in CNC milling machine using response surface methodology." Journal of Advanced Research in Materials Science 46, no. 1 (2018): 1-9.

[53] Rahman, M. D. A., Jaganathan, V., AMil, M. A., and CheRos, M. R. "Optimization of surface roughness on S50 carbon steel in CNC milling machine using response surface methodology." Journal of Advanced Research in Materials Science 45, no. 1 (2018): 15-26.

[54] Rana, R. S., Purohit, R., and Das, S. "Reviews on the Influences of Alloying element on the microstructure and Mechanical properties of Aluminium Alloys and Aluminium Alloy composite." International Journal of Scientific and Research Publication 2, no. 6 (2013): 1-7.

[55] Ronqueti, Larissa Agrizzi, Jérôme Favergeon, Marion Risbet, and Michel Picard. "STUDY OF GRAIN BOUNDARY OXIDATION OF HIGH ALLOYED CARBON STEELS AT COILING TEMPERATURE." 2016.

https://doi.org/10.5151/1983-4764-27735

[56] Seong, Woo-Jae. "Prediction and Characteristics of Angular Distortion in Multi-Layer Butt Welding." Materials 12, no. 9 (2019): 1435. https://doi.org/10.3390/ma12091435

[57] Sonia, P., Paswan, M. K., Saxena, K., and Singhal, P. "Review on heat and mass transfer in submerged arc welding (SAW) and gas metal arc welding (GMAW)." International Journal of Engineering and Advanced Technology (IJEAT) 8, no. 4 (2019): 503-512.

[58] Subramaniam, J., Ganguly, S., Suder, W., and Mukherjee, D. "Influence of welding processes on weld bead geometry." International Research Journal of Engineering and Technology (IRJET) 6, no. 1 (2019): 635-639.

[59] Thakur, A., Gebrelibanos, H., and Gabrey, T. "Arc welding process selection through a quality and costs." International Journal of Current Engineering and Technology 9, no. 3 (2019): 383-394. https://doi.org/10.14741/ijcet/v.9.3.6

[60] Tomkow, J., Fydrych, D., and Rogalski, G. "Role of bead sequence in underwater welding." Materials 12, no. 3372 (2019): 1-10. https://doi.org/10.3390/ma12203372

[61] Vempati, S., Subbaiah, K. V, and Raju, K. B. "Effect of residual stresses on the Ti-6Al-4V cruciform shape welded joints by XRD technique and influence of hardness - An experiment approach." Journal of Engineering Science and Technology 14, no. 5 (2019): 2928-2946.

[62] Wałęsa, Krzysztof, Ireneusz Malujda, Jan Górecki, and Dominik Wilczyński. "The temperature distribution during heating in hot plate welding process." In MATEC Web of Conferences, vol. 254, p. 02033. EDP Sciences, 2019. https://doi.org/10.1051/matecconf/201925402033

[63] Węglowski, M. St, and Tomasz Pfeifer. "Influence of a cutting technology on the quality of unalloyed steel surface." Biuletyn Instytutu Spawalnictwa w Gliwicach 58, no. 1 (2014): 13-23.

[64] Wood, W. E. "Heat-affected zone studies of thermally cut structural steels." Government Research Announcements and Index (1994).

[65] Xie, J., and A. Kar. "Laser welding of thin sheet steel with surface oxidation." WELDING JOURNAL-NEW YORK- 78 (1999): 343-s.

[66] Yadav, Jigesh, and Manikant Paswan. "Prediction and Optimization of Weld Bead Geometry." International Journal of Innovative Technology and Exploring Engineering (IJITEE) 8, no. 10 (2019): 2735-2742. https://doi.org/10.35940/ijitee.J9564.0881019

[67] Yuan, Qing, Guang Xu, Mingxing Zhou, and Bei He. "The effect of the Si content on the morphology and amount of Fe2SiO4 in low carbon steels." Metals 6, no. 4 (2016): 94. https://doi.org/10.3390/met6040094

[68] Zhang, Zhanhui, and Jiaxiang Xue. "Profile Map of Weld Beads and Its Formation Mechanism in Gas Metal Arc Welding." Metals 9, no. 2 (2019): 146. https://doi.org/10.3390/met9020146 
[69] Murariu, A. C., and Plesu, N. "Investigation on corrosion behaviour of welded joint in ASTM A355P5 alloy steel pipe." International Journal of Electrochemical Science 10 (2015): 10832-10846.

[70] Khalid, N., Zamanhuri, P. Z. N. M., and Shaiful Baharin, F. A. "A study of weld defects of gas metal arc welding with different shielding gasses." ARPN Journal of Engineering and Applied Sciences 12, no. 6 (2017): 2006-2011.

[71] Wei, P. S. "Thermal science of weld bead defects : A Review." Journal of Heat Transfer 133 (2011): 1-22. https://doi.org/10.1115/1.4002445

[72] Arivazhagan, N., Narayanan, S., Singh, S., Prakash, S., and Reddy, G. M. "High temperature corrosion studies on friction welded low alloy steel and stainless steel in air and molten salt environment at 650 degrees C." Materials and Design 34, (2012): 459-468.

https://doi.org/10.1016/i.matdes.2011.08.034

[73] Bhattacharya, D. K. "Failures of welded joints." (1997): 212-220.

[74] Kolahan, F., and Heidari, M. "A new approach for predicting and optimizing weld bead geometry in GMAW." International Journal of Mechanical and Mechatronics Engineering 3, no. 11 (2009): 1391-1394.

[75] Nur Azhani, A. R., and Ng, S. S. "Investigation of effects of MIG welding on corrosion behaviour of AISI 1010 carbon steel." Journal of Mechanical Engineering and Science (JMES) 7, (2014): 1168-1178. https://doi.org/10.15282/jmes.7.2014.16.0114

[76] Garcia, M. P., Mantovani, G. L., Kumar, R. V, and Antunes, A. "Corrosion behavior of metal active gas welded joints of a high-strength steel for automotive application." Journal of Materials Engineering and Performance (2017): 115.

[77] Votava, Jiří. "Protection of welded joints against corrosion degradation." Acta Universitatis Agriculturae et Silviculturae Mendelianae Brunensis 61, no. 6 (2013): 1897-1904. https://doi.org/10.11118/actaun201361061897

[78] Xie, J., and A. Kar. "Laser welding of thin sheet steel with surface oxidation." WELDING JOURNAL-NEW YORK- 78 (1999): 343-s.

[79] Al-Sarraf, Z., and M. Lucas. "A study of weld quality in ultrasonic spot welding of similar and dissimilar metals." In Journal of Physics: Conference Series, vol. 382, no. 1, p. 012013. IOP Publishing, 2012. https://doi.org/10.1088/1742-6596/382/1/012013

[80] Oussaid, Kamel, Abderrazak El Ouafi, and Ahmed Chebak. "Experimental Investigation of Laser Welding Process in Overlap Joint Configuration." Journal of Materials Science and Chemical Engineering 7, no. 3 (2019): 16-31. https://doi.org/10.4236/msce.2019.73002 